\title{
112 EFFECTS OF BROWN RICE (ORYZA SATIVA) IN THE DIETARY MANAGEMENT OF PATIENTS WITH TYPE 2 DIABETES MELLITUS
}

Erljohn C Gomez. School of Nursing, Centro Escolar University, Manila, Philippines

\subsection{6/bmjopen-2015-forum2015abstracts.112}

Background high in fiber that controls blood sugar levels. Currently, it is included in the Philippine National Unified Health Research Agenda for 2011-2016. The study will help patients with type 2 diabetes mellitus achieve optimal nutrition and prevent complications.

Objectives To determine the effects of brown rice on the following parameters- Fasting Blood Glucose and Random Blood Glucose levels, Blood Pressure, Body Weight, and Body mass Index.

Methods Using quasi-experimental design, subjects were purposively selected from Mandaluyong City $(n=24)$. The inclusion criteria are: 25-60 years old, diagnosed with Type II DM within 1-3 years, and without complications. Subjects were divided and randomly assigned into two groups. The experimental group received Harvester's ${ }^{\circledR}$ brown rice and were asked to take 1 cup of brown rice per meal daily for 8 weeks. The non-equivalent comparison group remained to eat white rice using the same measurement for the same period. Monitoring and compliance were assessed using scheduled and unscheduled visits of at least twice a week. Using measuring devices, laboratory test, and monitoring tools, the effects of brown rice in the five parameters were measured- FBS and RBS levels, BP, body weight and BMI. Devices were calibrated before the tests. The differences between the two groups were tested across all parameters using the Wilcoxon Signed Rank Z, Likelihood ChiSquare, and Paired Samples Student's t-test.

Result Those who were given brown rice showed statistically significant decrease in FBS, RBS, body weight and BMI from pre-test to week 3, 5, 7 and post-test (p-values $<0.05$ ). The effects of brown rice is significant as early as week 3 .

Conclusion Brown rice is an effective dietary management for patients with type 2 diabetes mellitus. Diabetic patients must be informed to include brown rice in their diet. These results provide basis for nurses in providing health education regarding positive effects of brown rice.

\section{REFERENCES}

1 Andales S. Why Filipinos should eat brown rice. Philippines. Accessed on: January 13, 20132008.

2 Behall $\mathrm{KM}$, et al. Whole-grain diets reduce blood pressure in mildly hypercholesterolemic men and women. Diet and Human Performance Laboratory, Beltsville Human Nutrition Research Center, Agricultural Research Service, US Department of Agriculture, Beltsville, USA. PubMed. Accessed on: January 13, 2013 2008.

3 Benaning M. Rice varieties safe for diabetics. Manila Bulletin, 2012. Accessed on: January 13, 2013.

4 The effect of brown rice in lowering blood glucose level for non-insulin dependent diabetes mellitus. Department of Science and Technology. Accessed on: January 13, 2013

5 DOST research extends brown rice shelf-life to six months. Science and Technology Information Institute. Accessed on: January 10, 2013. 